\title{
A well deserved honor: Yvonne Martin, 2009 recipient of the Herman Skolnik Award
}

\author{
Terry Richard Stouch
}

Received: 17 November 2009/Accepted: 19 November 2009/Published online: 11 December 2009

(C) Springer Science+Business Media B.V. 2009

Perhaps the only surprise about this award is that it was not awarded many years ago. As one of the earliest and most productive of the pioneers of the application of computational methods to drug discovery and design, Yvonne has covered all of 'the bases' of technologies and methods including a substantial presence in chemoinformatics. Most of us assumed that she was a recipient long ago. In receiving this award, she joins a line-up of other notables including Gerry Maggiora, Bob Pearlman, Hugo Kubinyi, Peter Johnson, Frank Allen, Johnny Gasteiger, Todd Wipke, and Peter Willett, to name only those whose names come immediately to mind and who also run with the drug discovery and design crowd.

The American Chemical Society (ACS) Division of Chemical Information (CINF) web page describes the award as follows: "The ACS Division of Chemical Information established the Herman Skolnik Award to recognize outstanding contributions to and achievements in the theory and practice of chemical information science. The Award is named in honor of the first recipient, Herman Skolnik." (www.acscinf.org/html/skolnik.html)

Guenter Grether, then Chair of the CINF Awards Committee, summarized Yvonne's award, her accomplishments, and her curriculum vitae in the CINF E-News, volume 10, number 1, Fall 2008 issue (ISSN 1559-7342) (acscinf.org/ docs/publications/enews/1001/1001.htm). A few quotes from Guenter's summary and letters of nomination follow:

"Yvonne was an early adept of QSAR modeling after spending a sabbatical year in Corwin Hansch's lab in

T. R. Stouch $(\square)$

Computational Chemistry, Lexicon Pharmaceuticals, 350 Carter, Road, Princeton, NJ 8540, USA

e-mail: tstouch@gmail.com
1967-1968. Overall, her contributions cover a broad range of topics in computational drug discovery including QSAR, pharmacophore modeling, structure based drug design, molecular diversity, and combinatorial chemistry. She was a principal developer of popular software packages such as DISCO and ALADDIN."

"Her studies in QSAR, molecular diversity, molecular graphics, pharmacophore analysis, molecular similarity and combinatorial chemistry greatly impacted the work of theoretical and experimental medicinal chemists."

"Her overall contributions have helped shape the modern definition of drug discovery. While she developed many methods and supervised their implementation, she never limited herself to a single method or application to solve real-world problems. She finds great pleasure in sharing her work with any interested researchers."

"She has been a founder and constant driving force in the development and use of computational chemistry and its application to computer aided drug discovery."

"Yvonne was one of the founders of the International QSAR Society (now called Cheminformatics and QSAR Society) in 1989 and served as its Chair in 20012005. Yvonne is highly respected by all of her colleagues worldwide and this Award is a well-deserved recognition of an outstanding research career."

Part of the award process is a symposium at the invitation of the awardee at the Fall national meeting of the American Chemical Society. In this issue, Wendy Warr treats us to a write-up of the accomplished group that 
Yvonne assembled. Typical of Yvonne, she used the award symposium as an opportunity to learn, enlighten, and reflect. Following is her description of how and why she chose the speakers

\section{Thoughts on organizing the 2009 Skolnik Symposium Yvonne Martin}

The Herman Skolnik Award is presented by the ACS Division of Chemical Information. Hence, it is fitting that the award symposiums recognize the contributions of those who collect and organize information for use by others.

Therefore, I selected three speakers who represent organizations that provide key data without which modern CAMD methods would not be possible. The vision and dedication of these groups to spend decades collecting data is something that I appreciate very much. Frank Allen represented the Cambridge Structural Database, the repository of small-molecule crystal structures. These structures provide the information on bond lengths, bond angles, and torsion angles on which force-fields are built. In addition, careful analysis of the crystal structures provides quantitative information about the variability and geometry of intermolecular interactions such as hydrogen bonding. Helen Berman represented the Protein Data Bank, the repository of experimental 3D structures of biological macromolecules, often in complexes with small molecules. These structures form the basis for drug and protein design and homology modeling, but PDB also provides data to support or refine theories of protein folding, relationships between protein structure and function, etc. Al Leo represented Biobyte that supplies Master, the comprehensive database of measured octanol-water $\log P \mathrm{~s}$ and $\mathrm{p} K_{\mathrm{a}} \mathrm{s}$ as well as BioLoom, a database of tens of thousands of Hammett equations for physical organic reactions and Hansch equations for bioactivities. The data in Master forms the basis of the CLOGP program that predicts octanol-water $\log P$.

James Dunbar represented the emerging effort at the University of Michigan, the Community Structure-
Activity Resource, which will collect accurate binding affinities and structural information for series of molecules; this information will be used to improve the prediction of the affinity of a ligand for a protein. The final talk in the database segment of the symposium was presented by Alex Tropsha, who warned the audience that just because something is in a database doesn't make it true!

I chose talks by Anthony Nicholls of Open Eye and Dick Cramer of Tripos to illustrate the impact of innovative thinking of software companies on drug design. Anthony reminded us that many of our methods are over-parameterized, even if we don't realize it, and as a result are not as predictive as we would like. Dick illustrated the use of Topomers to automatically generate a 3D QSAR and to support identifying potentially active, novel, and synthesizable R-groups.

Talks by several colleagues at Abbott Laboratories illustrated the impact of chemical information technologies in all aspects of drug discovery. Kent Stewart presented DrugGuru, a SMIRKS-based program that proposes medchem-validated transformations that can be applied to an input structure. Derek Debe described the system that he and his group developed to provide a wide variety of structural and biological information as well as computational methods to bench scientists. Phil Hajduk described the application of belief theory to the problem of selecting a subset of a database for biological screening. The objective of the design is to know the risk of missing an active chemotype. Steve Muchmore described the use of belief theory to combine results from orthogonal similarity searches to provide a leadhopping application to bench scientists. I talked about the utility of ligand-based methods in an era of structure-based methods.

Please join me in congratulating Yvonne, the 2009 Herman Skolnik award winner, an outstanding scientist, and a great lady. 